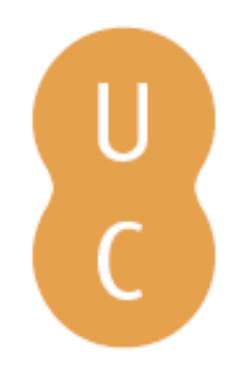

\title{
nombalina
}

Concept and freedom: on the forms of self-relation (Selbstbeziehung) in Hegel

Autor(es): $\quad$ Vos, Lu De

Publicado por: Imprensa da Universidade de Coimbra

URL

persistente: URI:http://hdl.handle.net/10316.2/31657

DOI: $\quad$ DOI:http://dx.doi.org/10.14195/978-989-26-0205-9_22

Accessed : $\quad$ 26-Apr-2023 09:34:30

A navegação consulta e descarregamento dos títulos inseridos nas Bibliotecas Digitais UC Digitalis, UC Pombalina e UC Impactum, pressupõem a aceitação plena e sem reservas dos Termos e Condições de Uso destas Bibliotecas Digitais, disponíveis em https://digitalis.uc.pt/pt-pt/termos.

Conforme exposto nos referidos Termos e Condições de Uso, o descarregamento de títulos de acesso restrito requer uma licença válida de autorização devendo o utilizador aceder ao(s) documento(s) a partir de um endereço de IP da instituição detentora da supramencionada licença.

Ao utilizador é apenas permitido o descarregamento para uso pessoal, pelo que o emprego do(s) título(s) descarregado(s) para outro fim, designadamente comercial, carece de autorização do respetivo autor ou editor da obra.

Na medida em que todas as obras da UC Digitalis se encontram protegidas pelo Código do Direito de Autor e Direitos Conexos e demais legislação aplicável, toda a cópia, parcial ou total, deste documento, nos casos em que é legalmente admitida, deverá conter ou fazer-se acompanhar por este aviso.

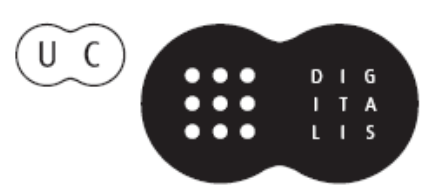


Edmundo Balsemão Pires

Burkhard Nonnenmacher

Stefan Büttner-von Stülpnagel

Editors

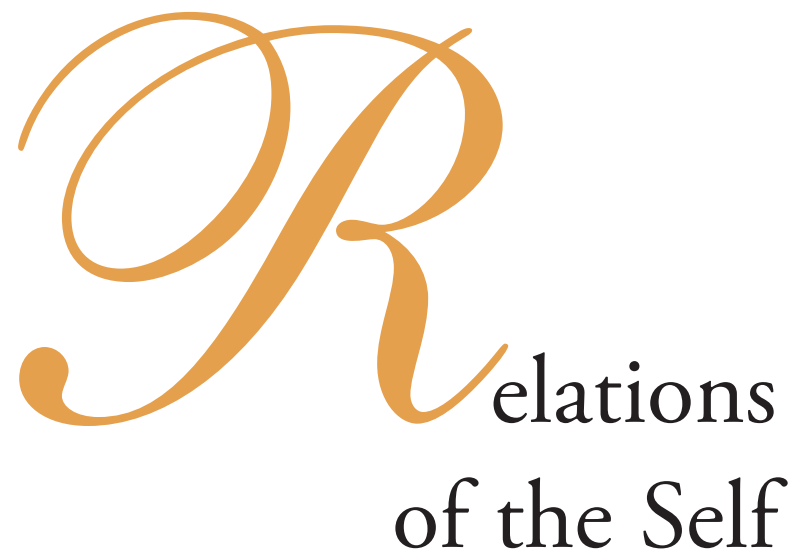




\section{CONCEPT AND FREEDOM: ON THE FORMS OF SELF-RELATION (SELBSTBEZIEHUNG) IN HEGEL}

In what sense can it be said that the concept or freedom are self-related? In an ordinary speech at least, it seems absurd to say that the concept, say of a thing, is related to itself. A cup of tea is a cup, but what else? Only in logic or in philosophy do concepts and things seem to be expressible as being 'themselves'. Furthermore, when the concept of freedom with its various negative and positive meanings is reflected upon, a kind of self-relation is indeed attributable to it. A self-relation, on the contrary, is in ordinary speech only attributable without difficulty to a speaker, one who uses such a self-reference to him- or herself. Problems arise in ordinary language and normal circumstances only in the speech of persons in certain functions. For example, when the king or president says or proclaims something, is he referring to himself as a person as such, or referring 'only' to his function?' Can a state or a company or a family, on the other hand, be said to be either self-related, e.g. in proclaiming laws, or self-referent, e.g. in engaging the whole in some action?

Perhaps none of these examples presents a self-relation as such. Is thinking in concepts such a self-relation? Or is that only the case for thinking about thinking? This may be so, but it should be argued that this kind of speech is not meaningless. Hegel's logic is just such a discussion, of a series of possible and perhaps real self-relations. Moreover, the concept and freedom are -for Hegel- the main topics of his overall doctrine of the concept ${ }^{2}$. In Hegel's own terms at least, subjectivity as self-relation is acknowledged to have a fundamental role. With the concept or subjectivity, the whole doctrine of what may be conceived, becomes a self-relation of the concept to itself. It is for Hegel the realm of subjectivity and freedom. This point seems quite clear, but in fact it is a continual source of possible misunderstandings and questions. How can a concept be said to open the possibility of freedom, if the concept elaborates formal systems? What sense of freedom could be present? Is attributing freedom to a system, which is fully understandable in its own terms, convincing? Why can and must such a systematic self-relation be called free? This last

\footnotetext{
${ }^{1}$ See the theological problems with the Pope, who is only infallible when he speaks as magisterium, but who is quoted after every speech, as if he were infallible every week.

${ }^{2}$ G.W.F. Hegel, Die subjektive Logik, in: Gesammelte Werke (GW), ed. by the Rheinisch-Westfälische Akademie der Wissenschaften, Hamburg 1968ff., Bd. 12 (1981); this edition will be quoted by volume and side.
} 
question will be the primary focus of this talk. The first problem, however, is that of the conceptual forms of self-relation, linked with self-reference.

In order to develop these problems in more detail, I will begin by considering selfconsciousness, in which its specific, defining moment is its use of self-reference. Selfconsciousness is an active self-relation (Selbstbeziehung) in its use (Verwendung) of selfreference as a performative act, in which there is an empty self-relation (1). I will then show how the connected problems of self-reference and ordinary reference are only resolved by and within spirit (2), which is a self-relation and self-knowing without explicit self-reference (3). Spirit is subjectivity, and only develops itself as a system of different moments integrated in and through the self-relation of self-knowledge (4). Spirit is not an individual entity; it has more complex systematic structures (5). None of them resolve the problem of precisely understanding and taking up the sense of self-relation together with its specific forms of non-ordinary self-reference. This leads to the notion of the Hegelian concept as self-relation, which resolves also the conceptual difficulties of self-connection (Selbstverhältnis) in its progress towards self and self-identity (6). This kind of subjectivity explains the formality of every system as a system of thought (7). Only the realisation and free actualisation the self-relation becomes for itself what it is, and the freedom of itself in itself and in all that could be other is the idea. (8) In fact, all of these-self-consciousness with its self-reference, spirit, the concept as well as the idea- are forms of self-relation, and all of them show themselves -in specific ways- to be free.

\section{Self-consciousness in its Use of Self-reference}

Let us start with a perhaps unproblematic notion of self-relation; anyone who uses a selfreference such as, 'yes, $\underline{I}$ am' or 'I see ghosts', is or has self-consciousness. Self-consciousness is namely the use of the concept of self, which appears in the possibility of using selfreference, 'I', in so far as self-consciousness attributes something only to itself, and in this attribution, as a use, appears as a self-relation ${ }^{3}$.

What precisely is the status of this self-reference as possible or appearing self-relation? Within this question, there is a more normal or even linguistic question and a more philosophical. The first may describe what is going on in a first-person use; the second asks for a kind of insight. In every case, self-reference has some specificity. There is the irreducibility of self-reference: 'I am here.' says something other than 'De Vos is here.', in as far as, of course, only I can use my self-reference in reference to myself ${ }^{4}$. Secondly, only an irrefutable and irreducible use of self-reference as such is possible. Furthermore, however, the use of self-reference seems to indicate self-consciousness; with that use, self-consciousness refers to itself.

The specificity of self-consciousness' relation is a philosophical problem, for, after all, what is that 'itself? It seems to be an empty reference, which is universal, namely, in so far

\footnotetext{
${ }^{3}$ Self-relation is a relation, in which the relata are not only related one to the other, but in which the elements or the relata are only understood and constituted by the relation in such a way, that the elements are singularised cases (Fälle) of their own relation. There is also a mutual understanding and producing of both, elements and relation.

${ }^{4}$ See H.-N.Castañeda, “'He’: On the Logic of Self-Consciousness”, in: Ratio 8 (1966), 130-157.
} 
as anybody might take it up, anyone who is able to perform this function. Even in this universality, it is only a basic (unhintergehbar) reference without possible error in relation to itself. Does that also indicate a thing, which is referred to, or given in the speech act? As it is only in its use that self-consciousness appears to itself: 'I am I' is a practical, never a purely theoretical, self-consciousness.

With that use, the problem -in philosophy- is to know what kind of self-relation is given or known, in as far as this use does not refer to a specific object, but rather indicates a user, which is only present as such in its use. As opposed to objects, to which there may be a reference and have perhaps only an attributed self-relation, this use of a 'self in selfreference reveals an abstract freedom, in as far as only the user may attribute with spontaneity 'I' or 'self to itself. The use of it is something abstractly free, in as far as this use arrives with the use itself. Why it is that somebody can refer to that self, is resolved in the act, through which the free performance relates itself to itself, for which the use of selfreference may be said to be basic practical knowledge. In this determination, the reference indicates only the user, but is now seen not as pointing to something, but rather as an empty form of self-related knowledge (in its indicating use).

In such a use, self-reference is not an automaton, in as far as such a thing could never say 'I'; it could say $X$, or give third-person attributes, but can perhaps never learn, under what circumstances it should attribute only first-, second- or third-person attributions. The use of spontaneity cannot arise out of something like a program, but rather only out of nothing other as itself, or out of freedom. For instance, why should a chess-computer learn to say 'I', in as far not it, but rather its engineer, is proud to have built a machine that has defeated of all the best human players? This counterexample indicates what the problem of selfconsciousness or self-reference is, beyond the free use. It is not just the use of this reference in abstraction, but also the use of the concept of self relation, that causes problems for how that use is linked to other tasks (or uses). The question is also how self-referent self-relation can be linked to ordinary reference, or how, in more classical philosophical terminology, self-consciousness and consciousness may come together. This self-reference as such is only problematic, if and in so far as the structure of the self-relation in its use of self-reference is taken up in its relation to all of what is referred to, or the other way around.

\section{The Relationship between Self-reference and Ordinary Reference}

Not for selfconsciousness that identifies itself by self-reference, but in philosophy, it is necessary to explain the fact that, in as far as there is a unification of the empty uttering selfreference, it seems, at the same time, both to be and not to be a reference to the body of the user. The self-reference does not indicate the body, but rather a 'self, namely the use itself or the user perhaps, but such a use is not some thing (etwas) given. In as far as, in the concept of self-consciousness, there is a difference between body and myself or between selfreference and ordinary reference, in which the use is related to something other, the philosophical approach to 'self-relation has to resolve this problem. ${ }^{5}$

\footnotetext{
${ }^{5}$ This is not meant as a substantial difference between animal and mental selfhood; the first can, if necessary only be attributed, the latter is nothing (i.e. not a specific thing), but knowledge, so that it cannot be annihilated, in as far as
} 
The form of being of the body is that of an animal, having a kind of living self-relation, without any self-reference, such that an animal body may indicate where it is, where its territory is, but without using something empty to say (and think) that it is itself in its use of self-reference. ${ }^{6}$ Life is also thought, not as a self without self, but as a purely possible self, which does not indicate itself and its position with a specific negative or universal relation. ${ }^{7}$ Such an attribution of the specific form is only an approach of philosophical knowing in which knowledge is transferred as not fully active, such that the self-reference may transform the self-indication into a form of universal empty 'I', or pure self-reference.

Because of this discrepancy between the only attributed and lived self-relation and the self-reference, it is impossible to remain with the I of self-reference as a final explanation. Self-reference indicates the bodily form of the 'empty' or (negative) self-consciousness, which claims to act itself and not as a body. Thus, the selfrelation of self-consciousness cannot remain with itself alone, in as far as it remains active or uses nature in a negative way in as far as 'I', with its bodily voice, indicates its place or body). Between the two, there is a negation, in as far as nature (i.e. my body) does not explain my self-reference, where my selfreference is also situated in my body (or voice). 'I am I' as a full explication of self-reference needs, for Hegel, to resolve the problem of how I am my own body or brain, or how the use of self reference and that of the reference (or life) and the 'I' of the conceptual self come together. ${ }^{8}$ If self-consciousness can be treated as an instance, where there is at the same time a self-relation (as in self-reference) and a reference (as in ordinary knowledge), and if the difference may be restated as a difference of form, between something that is at the same time something to be explained and something that explains on the one hand and something that is only to be explained on the other hand, then the discrepancy can be solved in a form of produced self-knowledge.

It is therefore only possible to connect both forms -life or body and freedom- if there is a specific self-relation (it is not an entity) that does not affirm abstract emptiness or negativity (of an irreducible use) as the essence of self-relation. It is the known shapes (Gestalten) of the struggle for life and recognition that negate the dualistic structure and antagonism, without annihilating the priority of the free self-consciousness ${ }^{9}$. These shapes exist for the sake of a philosophical progress or elevation from empirical self-consciousness,

self-reference is an irreducible use by the user itself; cfr. Michael Wolff, Das Körper-Seele-Problem. Frankfurt a.M. 1992; for an other approach, T. Nagel, "What is it like to be a bat? " in: The Philosophical Review 83 (1974), 435-450.

${ }^{6}$ With such a position, animal bodies are living their own organisation of their space/time structure, but without knowing that they themselves have in their self-indication a relation to itself as an own. Life has also, for Hegel, a form of subjectivity and is so 'for itself, in as far as it is organising space and time for its own drives and non-reflected motives; cfr. G.W.F. Hegel, Enzyklopädie der philosophischen Wissenschaften, GW 13: 160 (\$274).

7 The problem how life may attain and preserve its lived self-relation is not a further object of investigation; only the fact that there is a lived guarantee for a performance of such a potential self, is important.

${ }^{8}$ All these forms are for Hegel not ontological ones, but rather are posited by (philosophically developed) selfconsciousness, which is a form of conscious knowledge in as far as such a form has also to be explained, even if it is at the same moment used in the explication of 'itself' as a form of knowing. There is neither dualism of the material and the mental nor reduction of all the mental to the material (nor the other way around). This difficult state of affairs may said to be the rational and philosophical problem of the normal use of every-day self-consciousness.

${ }^{9}$ G.W.F. Hegel, Enzyklopädie, GW 13: 203 (\$ 358). 
which is only related to itself in its abstraction (or in its abstract use) or to an universal, in as far as this has, with self-consciousness, the form of a beginning and permits the properties of 'strict' self- reference.

Such a universal self-consciousness and also reason are vitally important, in as far as the difference of consciousness, through which there is an opposition to consciousness, is overcome in a definite way (i.e. surpassed in every day life, and explained in philosophy). Through such a form, the integration is realised by a self-relation, which is able to attain a unity of the differences of related moments. However, it seems that this is attained at a cost: limited individuality must be given up, together with the opposition out of consciousness, ${ }^{10}$ if there is to be a reason in existence, which is spirit ${ }^{11}$.

\section{Spirit: Self-relation without an Articulated Self-reference?}

Only spirit can achieve self-knowledge, or a self-relation in which self-reference and reference to an other can be structurally linked. From this moment on, the self-reference that is specific to self-consciousness, is transcended in view of a possible (Hegel would say more fundamental) self-relation: spirit. Spirit, however, is only the self-knowledge of such a form, starting with philosophical self-consciousness as a possible, empirical, irreducible use of selfreference, which remains an instantiation. Insofar as this spirit arises (philosophically speaking) out of the self-conscious individuals and it presents such individuals as its singularisation, spirit remains open to individuals, but is never submissive, or otherwise at the disposal of them as such.

This spirit is (and subsists) only in so far as all otherness or strangeness -either perceived or represented - is no longer a product of an individual knower, but rather in so far as they are its own production, of its own realisation of the different cases (Fälle) of spirit itself. Spirit exists, where it is and it is there, because we, individuals, all try together to know and act and because we try and realise our own emptiness (now as freedom) as a universally valid possibility of shaping in knowledge and action, and have all affirmed and realised ${ }^{12}$. This

${ }^{10}$ With this 'progression' or elevation there are many further impossibilities in a reflective use of 'self: There is no self-observation; what can be seen and recognised are things and perhaps actions, but not a self-referencing self; i.e. the voice can be heard, the meaning can be grasped, but there is no observable (theoretical) entity 'self, neither outer nor inner. Such a talk would be a relic of Cartesianism and dualism. In the same way, being-self (Selbstsein) is only an ontological version of other sciences (and even philosophy) in which the moment of individually indicated use of a supposed entity is isolated. Self-conservation (Selbsthabe) is a done return of some to its own proper individuality, but such a self can never be thought in a sense full way; such a concern about myself alone will be thought of by Hegel as 'the bad', in as far as it is or consists only for itself against its spiritual challenges. The further forms of egoism as self-related in this negative sense are further concrete forms of ethically bad self-concern, self-relatedness or self-interest as egoism, family-egoism or the egoism of groups (either within or as a nation).

${ }^{11}$ W.Jaeschke, Hegel-Handbuch. Stuttgart-Weimar 2003, 351.

${ }^{12}$ For specific non-philosophical sciences, there may be given (or constructed) specific entities, individual selves (like individual members of the human species) as well as social roles and institutions for them, in which all seem to use different forms of self-reference. Spirit on the other hand is only a philosophical name and concept: neither in our ordinary life, nor in the sciences, there is given a spirit, in as far as such a concept, as well as that of (pure) self-consciousness, not is referring to a preconceived entity; such non-ordinary concepts are only produced 
spirit is also the philosophical principle or the ground of explication, which nobody can avoid in his or her theoretical or practical claims about (self-)knowledge. ${ }^{13}$ Self-knowledge is therefore free, in so far as it builds up actively the forms of its freedom, as a self-relation not only related to itself; such a self-relation is every time contental, in as far as it brings together the different forms, either as consciousness and self-consciousness or as theoretical and practical knowledge of something other, within its own forms. In ordinary language, one could say that it's the self-related (or free) presupposition of all non-self related (practical) knowledge or, in other words, of our common basic framework in real (acting) existence.

This spirit is in its first form, as subjective spirit, neither a property nor a state of an individual subject, but rather a philosophical form, which is the guarantee for the universal validity of even our perceptions or intuitions; a validity that is needed and presupposed by a new form of experimentation for coming to an accepted belief. With subjective spirit, the specificity of the concept of spirit, to be at the same time known and to know, is in this way fulfilled ${ }^{14}$. The emptiness of nature (shown first by self-reference) has now come into its an universal and arguable position in freedom, in as far as it is not further posited in opposition to nature, and nature as an object (Gegenstand) of intuiting, representing or thinking knowledge is taken up as the occasion of this shaping (Gestalten) and reproducing it with a specific spiritual meaning in action. Furthermore, that relation of knowing and the known, and of acting and action is, as self-knowledge, a form of self-relation.

It is important to note, however, that the 'self or ownness (not inwardness) of selfconsciousness is not annihilated, but rather fulfilled by the whole of spirit. Spirit itself is not an individual; therefore it does not use a self-reference, although a self-reference may be elaborated out of it. 'I am seeing or doing', is part of the phenomenal or empirical process, which is given with the philosophical concept of subjective spirit. For the process of knowing or acting, there can be isolated forms, which attribute (an also empirical 'proud') self-reference to themselves. Therefore, self-knowledge is not an automated program, already fulfilling itself when begun, even if there is no need to translate it again to the first-person. It is only self-related persons who are involved in the first possible free acting of spirit, in thinking and doing or who form the specific 'isolated' selves of self-knowing. It is just in the subjective spirits, who realise the spirituality of possible spirits as their own activity, that the relation of spirit to its own specificity appears.

or constituted with the use of that concept, linked in self-consciousness by self-reference. In the case of selfconsciousness, the user ascribes to himself this conceptuality and is not mistaking himself with that ascription; in the case of pure consciousness, this concept is necessary to explain the use of I as (hidden) form of knowledge; in the case of spirit, it is a user, who is aware that he is claiming rationality and recognised awareness in its use, in such a way that he may take up that (philosophical) concept in view of philosophical elucidation. Cfr. also H.F. Fulda, G.W.F.Hegel. München 2003, 183-4.

${ }^{13}$ Saying, 'I know or want p', or better, 'we know or want p' or 'Spirit knows or wants p' is a fulfilled act of true self-relation as knowing or doing, even if the following empirical fact known or project ('p') is false or unrealised.

${ }^{14}$ G.W.F. Hegel, Enzyklopädie, GW 13: 204-223 (\$ 363 -399). 


\section{Spirit as Subjectivity and System}

Spirit as such realises subjectivity, or, in other words, an own contental self-relation. Subjectivity is -and so may be defined as-an active unity or affirmation of different forms or moments, which reproduces the necessary conditions of its genesis (consciousness and selfconsciousness) as the moments (both theoretical and practical) of its own production (i.e. being free in its moments). Spirit is thus the affirmation of its aspects, in as far as it is the sufficient ground for all of the previous stages, like soul, consciousness, self-consciousness and reason ${ }^{15}$. It is existent reason; it is (practical) self-knowledge; it is consciousness of its world and it is actively aware of its own world. Minimally, it takes up all these pre-forms into itself and contains and grasps them as itself. Subjectivity (therefore) is not a specific class of things, but rather an affirmative (self)-relation of specific thoughts, which are lived and (practically) understood in ordinary life as well as conceived of as such in philosophy. In the performance of these self-related thoughts, knowledges or actions, there is subjectivity, which never before grasps, produces or conceives of these determinations themselves. Thus, spirit seems to have, as its (theoretical) property or its (practical) essence, freedom. Subjectivity is a free activity positing itself (not against the other but with and within the other). -- In Hegelian terms, this 'retaking yourself in these others' is then also freedom.

With subjectivity, a system of different moments is in principle given (in spirit, not in self-consciousness), which may be described (in an abstract theoretical way) as functions. It is not self-reference, which indicates only an (empty) ownness (Eigenheit), that is systematic -that ownness is only an abstract or ideal form of subjectivity; it may be a specific form (even necessary as bare specificity), but it is not the structure of subjectivity. For in this structure, there is a minimal production of ownness in otherness, in as far as the world is discovered in language and thought and the realisation of spirit exists through the different instantiations of such activity. Self-reference, not able to link or relate itself to itself in a more than empty way, exists, but with spirit as subjectivity there is a (spiritual) content. The self-relation has related forms, which are there in their spirituality, only in as far as they perform a (singularisation of the) self-relation ${ }^{16}$.

Thus, spirit seems, already in its 'subjective form', to be a possible system ${ }^{17}$. This spirit is a production, which takes up and grasps its moments, the realisation of an initial system, whose parts or moments are taken into account under its own properly produced (law of) self-relation as free. It is just this affirmation (within a complex structure) that shows it is subjectivity and -very strangely, for normal understanding- subjectivity is not restricted to claiming its ownness only for itself, but, more important, also systematically presents itself in other forms as well. In the system, in its use of self-relations, there are more moments

15 G.W.F. Hegel, Enzyklopädie, GW 13: 205 (\$ 363).

${ }^{16}$ The empty self-relation has only its self-reference as its form, which makes abstraction of or is negatively linked with other relations. Self-reference is thereby not a singularisation of a previous self-relation, but the simple actual and expressed (produced) own self-relation itself.

${ }^{17}$ A system is a totality, articulated on the basis of a principle for that articulation, and it is only self-related on the basis of that principle, which takes up the elements as itself. If the elements are viewed in their relation to one another (or to the -presupposed-principle), such a theoretical version is enough for (non-philosophical) science. 
which are connected; and in its function as a system, this connection is to be found in the activity of affirming (i.e. unifying and in the act of bringing together) different forms. Every form of system is therefore shown to be a variety of self-relations, where all the different types of self-relations should be organized ${ }^{18}$. Therefore, there are further developments within the system, in so far as only one system of philosophy must be posited. The system is the form of a true philosophical grasping, insofar as reason (through its individual principles) and spirit are systematic. The notion 'spirit' also guarantees or realises what is (in transcendental philosophy) claimed for reason or I; that its very structure is the ground of the systematic unity of reality. Spirit is thus a knowing and productive system of spirit.

\section{Complex Spirit}

This subjectivity may seem to be a simple result; but it will elaborate itself into a more complex form, in which the principal systematicity of its own activity will be presented. Here, the full structure of systematic subjectivity is developed, in which the differences of the theory and practice of spirit are now posited in freedom, in as far as the attained level of subjectivity is not only asserted against other or simpler moments, but these moments are also elaborated for themselves.

With this elaboration of the forms of the system of spirit, the system of spirit demonstrates the following: it is not objectivity-without subjectivity or without freedomthat is posited, as if subjective spirit were a kind of foreign organisation of spirit that it is not nature, but only a second, produced nature. The forms of subjectivity are not purely observable (or calculable); all the different forms of system may provide the opportunity for further empirical research, and this empirical research is taken up, and elevated to the level of a conceptual structure, in philosophy. ${ }^{19}$ None of these 'systems' are loose or disconnected from one another (or autarkic), but they are related to one another and know through the philosophical notion of 'spirit', which is neither the simple human person nor the simple 'subjective' instantiation thereof.

In so far as they are conceived of as philosophical thoughts (even as singularised), all systems are conceptually built up around the notion of self-cognition and freedom. They are not built up by individuals, but by spirit, i.e. by the individual singularisation of the differentiated notion 'spirit', e.g. the family, or the state, in which persons build up a system, which is not in their power, but is its own proper subjectivity, grasping different persons. This subjectivity (or system) is not self-referent, but rather related to itself in all of its institutions, and thus self- related in as far it appears as a unity or affirmation in such institutions, recognised in philosophy as systematic forms of spirit.

\footnotetext{
${ }^{18}$ In so far as, within subjective spirit, the moments are described as faculties or functions, there can be empirical research about soul, consciousness, self-consciousness, and references to things in terms of self-relation and selfreference; in their mutual link as forms of (produced) knowledge, they are taken up afterwards in philosophy.

${ }^{19}$ If scientists propose that there is a system, they transfer a philosophical notion, in which reason or spirit is posited as a system, to theoretical research and presuppose the basic principle(s) in their empirical and theoretical claims; in this way, the systematic self-relation of elements within their system is attributed from 'the outside', by the scientists.
} 
In all of these self-relations of spirit, there is no ordinary self-reference within the forms of the system under consideration. If there is a complex self-reference, there is a kind of place but not an instance that simply exists (e.g. the state). In complex spirit, there is also no direct or no ordinary self-reference. ${ }^{20}$ In subjective spirit, the singularisations are in principle all subjective, but now, in complex spirit, the functions and roles are different.

No thing and nobody could truly say, "I'm the complex spirit", whether it be a state or the family, but persons can be taken up as functions within that system. Some persons can speak in the name of the state or the family, e.g. "Now I decide to make war (not love!)". Some persons can even decide to reorganise such systems. A state contains individuals as its body, organised as an institutional possibility, in which the state appears, such that there is a more complex system or subjectivity of the state. In this case, the self-relation exists for everybody. "We are all (equal citizens) of the (democratic) state"; the self-reference is not a direct one, but rather an institutional one; (empirical) uses of self-reference within such institutions are not sufficient to have the knowledge and free possibility to act within or influence that institution. The self-relation, only to itself, of subjective spirit is a mistake about what is subjective in its exposition. Only one can subscribe to the laws, and proclaim war and peace, and so on. In such an act, the king may say "I am the state", such that there seems to be a self-reference of the king, but in fact this is only a function or role within the state itself. ${ }^{21}$ If the king decides (in the name of the state, which as an institution or complex spirit decides actually) to start a war, the self-reference is not localised within or necessarily linked to a specific body (e.g., in the formation of new states). This demonstrates the (empirical or sociological or political or juridical) problem of a kind of new emptiness, of every self-reference. The self-relation of the system is not an instance of self-consciousness, nor even of subjective spirit, but only of the institutional (or organisation or specific system of) spirit.

Systems such as states and even economic markets may be theoretically described as functional systems, but they are never automatons without subjectivity, in as far as, philosophically speaking, system and (now realised) subjectivity are linked. Even if they are in a sense not accessible by every person, there are systematic laws, such that a person can have insight and make changes. It is not that everybody is responsible for every act and must have enough insight; and in as far as there are rules that can be changed through discussion, it may seem that there are personal motives such that -even if they seem to be connected as or by invisible powers- the strict decisions of institutional forms (e.g. of laws) are open to reflective and personal deliberation and proclamation. ${ }^{22}$

\footnotetext{
${ }^{20}$ Let's elucidate (negatively) with religion: in some religions of the Book, God Himself speaks with a reference to Himself. If somebody tries to speak in the name of his/her God, (s) he is only referring to an other voice, in which it is claimed that God shows His existence. Hegel will accept the significance of such a religious God, but His meaning is restricted to the self-relation of spirit, in which case there is no need for an explicit self-reference by voice, but only for the highest possible self-relation.

${ }^{21}$ If the king would be captured, immediately someone else would take up his function, either as a regent or as a new king.

${ }^{22}$ That complex spirit is neither the action of only one (patriarchal or dictatorial), nor the power of some against a great and enduring majority. And even if impersonal forces are there within that complexity, these are acting forces in which different people are contributing really. Even if our economic crisis is not foreseen (and in
} 
With complex systems of spirit, which are not presented here per se, but only covered in principle by (or alluded to in) my remarks, there remains the problem of the (conceptual) self-relation or subjectivity itself. Spirit is said to be self-relation in the form of presenting or active self-knowledge, but what does that self-related grasping of moments mean? What can be conceptualised by self-relation in systems of spirit or self-knowing? To take a philosophical (Hegelian) approach: spirit is perhaps only an example of the concept. Grasped in its selfknowledge, based on (pure?) self-relation, spirit indicates (for Hegel) the concept, where earlier moments of that spirit as well as the presented moments of spirit come together. By establishing itself as a self-relation or subjectivity or system, spirit exemplifies such concepts, in such a way that empirical consideration may also be grasped as coming to indicate selfrelation or system, although they are not argued as such in their thought, philosophical content. After trying to give some examples of specific self-relations, which are not logical, but spiritual, the problem now will be: if there must be a fundamental exposition of conceptual forms, as outlined in Hegel's science of logic, it is clear that spirit exemplifies those concepts but that only logic is able to establish the true essence or conception of these forms. Therefore, the logic of the concept itself must now be taken up.

\section{The Logic of the Concept}

Only concepts perform and thereby explain their own relation to themselves. The arguments for this position seem simple: the first argument may be negative; there is no reference (empty, concealed or non-ordinary) used in self-relation at the level of the concept, in as far as every reference suggests a difference between an entity and the appropriating, knowing or acting form. However, it must be explained what and how self-relation is to be conceived. Even spirit in its self-cognition is not able to function without any reference, in as far as spirit comes up out of a irreducible self-reference, or at least, from the point of view of normal consciousness or understanding, there remains the suggestion that there is an essential difference between subjective and objective forms of itself, which are (philosophically speaking) essential forms of itself. It is self-relation, not self-reference, which is at stake here.

The second, positive argument is even more simple, but the totality of implications thereof is vast and difficult. The concept builds up in principle only a concept, as a logical or formal relation (not reference) to itself. ${ }^{23}$ But what is such a concept, and does it really explain anything? Why is that concept not an empty one? How is this to be explained?

The concept posits (at least, for Hegel) that "which is in and for itself," as itself; and that may said of every (pure) concept ${ }^{24}$. The concept is defined in this way as an absolute unity,

\footnotetext{
that sense not consciously produced), it is at least the product of actions of persons (in financial institutions), who have monopolised dubious forms of money-making, and are followed by lots of interested other people.

${ }^{23}$ For V. Hösle between the features of logical concepts seems to belong also their self-reference (V. Hösle, Hegels System, Bd. 1, Hamburg 1987, 72); logical concepts may be predicated to themselves, either in their totality or in some cases (Fälle), this, however, is not a self-reference, in which they are irrefutably referring to themselves, but only a predicative self-relation.

${ }^{24}$ Cfr. G.W.F. Hegel, Wissenschaft der Logik, GW 12: 16 .
} 
such that the 'in and for itself' is posited, as well as that of the position itself. Such a concept has some presuppositions. It cannot be conceived without previous moments. These moments may exist as real knowledge or, in Hegel's terms and conception, as 'being' and 'essence'. ${ }^{25}$ Even starting with thoughts, the concept presupposes the act of elevation of philosophy from out of natural consciousness, such that this may be said to result from freedom. However, the reconstruction within logic demonstrates the ground of this (possible) freedom in the self-relation attained with the concept. ${ }^{26}$ This means, for the purposes of our presentation, that there are no things such as natural ones, and not even those that know themselves sufficiently in negative relation to things, like spirit in its self-knowledge, but only a concept of the negative relation of being to itself as being and as reflection, which is then the explication of itself. Also, the concept is said to be the truth of substance, which is, in our account here, clearly the case for spirit. The fact that the concept relates to substance is specific to Hegel's manner of presenting the genesis of the pre-forms of the concept.

With the unity of substance, the last explication of what could 'be' and could 'be reflected' is given a necessity. Such necessity could have the meaning of an automaton, that only reproduces identity, but this explication of substance is only passive; if the forms of substance could relate to themselves, the relations of something that posits the other as itself are produced. For spirit, this is realised there, where every knowledge (even the natural one) is produced as conceptual knowledge, i.e. in philosophy. All forms are their (conceptual) cases in themselves, and are thus only the structure of the concept in itself as well as in its other.

The concept is free, as identity in and for itself, which takes over the necessity of moments of the substance, (even within spirit), but therefore, the concept is posited; and its position is a self-related one. Spirit has in itself not only moments of itself, but also the moment of nature as reworked and taken up into spirit, which is itself not fully self-relation before the conceptual endpoint of philosophy. The subject-matter of the concept is the cause of itself, or, in other words, it is the substance "liberated to that what it is in truth" (free for itself). ${ }^{27}$ The relation of concept and freedom in that explication discusses the status of conceiving and freedom in just this logical, grounding sense. For, the concept is the realm of subjectivity or freedom. In the concept, the absolute negativity is posited and is positing itself; in this way, it is therefore freedom, which is the identity of the concept, being negative even against the negativity of reflection, which is an initially concealed difference, opposed to being. In the concept, the realm of freedom is thus opened, as the concept in its presentation is the truth of essence and the freedom of necessity.

The concept is related negatively to concepts that do not develop themselves, like substance, but which exist only in the (philosophical) exposition as forms of the concept. In claiming that they are not conceptual, and in trying to explain themselves, having knowledge within spirit or being reflecting as substance without the sufficient conceptual means, they are the

${ }^{25}$ Cfr. G.W.F. Hegel, Wissenschaft der Logik, GW 12: 11.

${ }^{26}$ The concept is producing itself to its own ground. The previous forms, being and essence are taken up in their unity and truth in the concept; cfr. for the concern of Hegel's science of logic: H.F. Fulda, G. W. F. Hegel. München 2003, 101-123.

${ }^{27}$ Cfr. G.W.F., Wissenschaft der Logik, GW 12: 16. 
very negative distinctions within the concept itself. All of these negatively distinctive forms are (at least, for Hegel in his science of logic) elevated from out of ordinary understanding and treated in their pure use. And the use of these properties in (philosophy of) nature as well as in (that of) spirit is only a supplementary use of such conceptual means, which for Hegel follows the pure conceiving.

The concept is in this way formal subjectivity. Subjectivity is an affirmation and exposition of different forms or moments, which reproduce the necessary conditions of its genesis as moments of its own production. What appeared in spirit now takes on a radical form: there is no being at all, no reflection, and no entity, but only concepts, in and through (pure) thinking. Minimally, subjectivity takes them up into itself and contains them as itself, as well as conceiving them in and for itself. Subjectivity only exists if it is capable of taking up the moments as its own presupposed forms, and to recognise them as its own. ${ }^{28}$ In this way, the concept reconstructs 'being' and 'substance' (and in a different way nature and even absolute spirit), and that is in terms of the (formal) concept, in as far as only concepts can grasp concepts. The concept, unlike spirit, does not conceive directly concepts of nature or of ordinary and complex spirit; it is rather concept in a strictly formal sense. Subjectivity is therefore not a specific class of things, but is rather a relation of specific thoughts, related to itself. In the performance of these thoughts, there exists a subjectivity, which never, prior to this moment, thinks or conceives of thoughts, just as spirit is self-knowing or free only in exposing itself in relation to the moments of itself. The structure of the concept constructs (i.e. reveals) or reconstructs every thing and reflection as a moment of an and, now, of the concept.

The concept must know and recognise the moments as forms of itself, and indeed as itself, and only by this act can something be conceived. The forms of conceiving the concept form the kernel of such (universal) concepts as subjectivity and system (as activity). In this way, the concept presents a formal doctrine, which produces and presents thinking and its forms or in its forms as formal subjectivity. This 'first' subjectivity may be specific, but it will not be the real subjectivity of the concept. There, its existence does not lack the concept (and that is shown also by spirit ${ }^{29}$ ); the point therefore is that it is only the case if the concept is as a singularity, ${ }^{30}$ in so far as the concept seems to be only a form or formal.

${ }^{28}$ Cfr. L. De Vos, 'Subjekt', in: P. Cobben e.o. (ed.), Hegel-Lexikon, Darmstadt 2006, 430-434.

${ }^{29}$ There are two important forms of self-relation, which are themselves grasped as subjectivity or system, spirit and the concept (or the idea). The difference between them, the (practical) self-knowledge of spirit on the one hand and the conceiving of the concept on the other point to the following: spirit is in its meaning and structure (non as a concept) available for everybody either in the sense of (subjective) thinking and affirming or -more certain- in the sense of objective acting in a (political) community. Spirit, however, is not accepted in every sense by normal understanding as a possible system. Only in and for philosophy, spirit as subjectivity is an or the system and also the or a concept; the explication and foundation thereof is given by the concept, which is as subjectivity the elaboration of the system and as system an activity of pure thinking (or even subjectivity as such). Spirit is thus for everybody and not only in philosophy the singularisation of a self-relation (as self-knowledge), which has to do with a fundamental active subjectivity.

${ }^{30}$ The German term 'Einzelheit' is to be translated as 'singularity', in as far as Hegel distinguishes between the natural and living individuality (as case of a 'natural' genus) and singularity as only a specific form of the concept (Cfr. G.W.F. Hegel, Wissenschaft der Logik, GW 12: 49). 
In as far as the concept has to present its own moments, and this presentation is not a simple relation, but an affirmative self-relation, the concept needs its own moments, which are forms of negation, but now identified as its own negations $s^{31}$. In producing a self-relation, there is the affirmation of different moments as its own and in a possible presentation (minimally affirmed as a judgment, and better yet as a syllogism) such that the concept needs a negation within it, but is not restricted to the movement of negation to itself as negation. Moreover, the affirmation is an act of presenting forms as related to the full structure and therefore free, not a theoretically or abstractly observable necessity of the forms of negation. ${ }^{32}$ Every concept posits as its own universality its own (produced) conceptual structure. And this conceptual structure is an active form, such that the form as such may be theoretical, but the activity is a performance (or an act of freedom).

\section{The Concept as Formal System}

The structure of the concept or of subjectivity not only explains the system as such (or systematicity, what was shown in act, as formal), but also produces it for the first time as conceivable. Subjectivity grasps and posits moments. In this way, it presents itself in forms of itself in such a way that the differences are related, not to themselves, as in identity or substance, but to itself ${ }^{33}$. This is first accomplished as an ideal form: i.e., the system of formal logic as forms of a system in which only the self-relation is spelled out (or which

\footnotetext{
${ }^{31}$ The concept as subjective explains its own (conceptual) pre-forms of self-relation. These pre-forms are distinct of the concept, and also a real pre-shaping of subjectivity. Therewith, the concept takes up its difference with 'being'; the established difference with being shows the concept integrating difference (or negativity). The concept has also a difference relative to reflection, even to reflection as the negation of negation, in as far as the concept is an affirmation. The negation of essence going to itself would be sufficient, if there was no need to give a proposition (Aussage), with a form of affirmation; such a particularity of relating being and essence cannot be accomplished by one or both, but only in a next specific form.

${ }^{32}$ With a historical allusion, even if Hegel seems to relate the concept with Kant's 'I think', the best minimal structure of Hegel's concept is the structure of the (Kantian) fact of reason.

33 Subjectivity exists only against and with other forms, which are necessary for the notion of the concept, i.e. the actively conceiving conceptual moments; thus, subjectivity is the affirmation of a self-connection (Selbstverhältnis). If the concept in its simplicity is everything, then the other forms are only concepts (i.e. for philosophy, in its distance to normal understanding and after evaluating the ordinary forms of the use of concepts in ontology and reflexive understanding). From this moment on, all these forms can be interpreted in such a way that they are 'given' and 'found' concepts, as if they could simply be described, and before the attainment of the concept in its distinction, there are nevertheless also specific 'resulting' forms of self-connection (Selbstverhältnis). The philosophical position or claim is taken up, if they are all taken to be the necessary structure (the 'body') of the (free) activity of (free) conceiving. In the doctrine of 'being' (G. W. F. Hegel, Wissenschaft der Logik, GW 11: 33 - 232), and of 'essence' (G. W. F. Hegel, Wissenschaft der Logik, GW 11: 233-409) there is the preparation of fundamental necessary concepts to conceive of the determinations of subjectivity (or conceiving). How does it work in being? From the point of view that there could be a meaning and use of that concept, there is a doctrine about these forms, but not a real system. 'Something' as the (ontological) negation of negation is the beginning of the subject or of the formal version of the concept as existent. How in essence? Through the acceptance that 'being, which is no simple being' can be articulated. In minimal grasping something as identity with itself, there is the logical self-connexion of every logical determination. But even here is only a doctrine and partial systematical elaboration (with specific properties), but no system.
} 
remains in the manner of a pure subjectivity). With such forms of the concept related to themselves alone, these forms are the logical elaboration of subjectivity in a systematic way. ${ }^{34}$

The subjective concept is formally differentiated as universality, particularity and singularity. Only as singularity is the concept existent as concept. The problem for singularity lies in taking up the structure of the concept, which must derive, out of itself, a full simple structure, which is not present in non-formal concepts in the same way. If universality is the structure of systematicity, and its particularity is grasped as a particular case (Fälle), or if Particularity is as self and Universality is a further 'genus' posited with it, assuming a further systematisation, as if that kind of concept gives itself its own law, then there is a concept, presenting for itself both simple determinations, as determinations of the (formally realised) concept. ${ }^{35}$ But this very structure was produced in grasping other moments in the emergence of the concept as subjectivity or self-relation. In this case, the concept shows itself in its formality. In showing how every concept is a form of the concept, the universality of the concept is linked (i.e. particularised) to itself, such that it is the same concept, which exists. Thus, singularity is the form of active self-relation ${ }^{36}$. Or, in other words, every singular form can be 'thought' (by thinking) as being in a kind of self-relation or as a form of subjectivity. Thereby, only the specificity of the concept (which is in and for itself) is presented for itself (but not for itself alone).

If the singularity is only the specific self-relation of the concept, then this would indeed indicate only a formal existence. Singularity is the form of real self-relation, grasped as formal. But it is just through such a formal realisation that it is an existing case. There is a subjective form about which there may arise attributions out of the differentiated moments of the concept, such that it is a formal self-relation. From the moment that this singularity is taken as a subject of a judgment, it is reduced to a (theoretical) form of (or for) normal understanding and it is (for formal understanding) no longer free, but only (for philosophical conceiving) appearing as freedom. Here, there is the concept, as an articulation of itself, out of which follows a being only that is through the production (non-being) of being. Here, for the first time, there is a system of forms (a formal logic, but not as an isolated, separate discipline). But where are the further forms of 'the' system? ${ }^{27}$

Can this 'thinking thought' develop itself without freedom, as if it were a computer program? Only if it were a mechanical necessity, only if it is conceived of as 'dialectics' in general, as if there were nothing but just the process from beginning to end, the elements of which are -in this case- only ever theoretical (or technical?) forms. Of course, this is not the case, insofar as its philosophical elaboration is performed in opposition to arguments and

\footnotetext{
${ }^{34}$ Can it be said that there is a self-reference? No, in as far as it is not the proposition itself that uses itself to indicate itself, as in the case of self-consciousness; nor as in the case of somebody who takes up the indirect, complex self-reference in cases like the state; such a proposition is only indicating the limit of sense full speech.

${ }^{35}$ G.W.F. Hegel, Wissenschaft der Logik, GW 12: 49-52.

36 See Kl. Düsing, Das Problem der Subjektivität in Hegels Logik, Bonn 1976.

${ }^{37}$ The resulting subject of judgment is also crucial; it is attained at the level of singularity, in such a way that some conceptual features may be articulated or attributed to that subject in view of the explication of what is conceived. This attribution shows the simple negative and positive self-relation of subject and attribution in judgments and in syllogisms, which relate all forms of the concept in their conceptual universality, particularity, and singularity to one another.
} 
positions, such that the (singular) subject of judgment is not given, but is instead built up. In this building up, thinking is the exposed self-relation of freedom. This relation, however, is only a performative one, and so it is free. That concept, freedom, is indeed the performed or self-performing self-relation. If the concept would be understood only theoretically or formally (as the empty determination of an alien thing), then there would be no basic (practical) freedom in the performance of even the most minimal singularity.

The system as a totality (or structure), that seems to be closed, may attribute a systematic form to the doctrine of being or doctrine of essence, in as far as the first is formed through negation (attributed to essence) and essence is formed by a further negation (attributed to conceptual self-reflection). But a system, properly speaking, is only present if there is a new form that organises that content with a principle. Such a system exists in a formal sense in the full elaboration of formal subjectivity; that formal thinking is not related only to itself is seen in the position of formality or simple subjectivity. Even if it seems that there is no difference between concept and freedom, just in the manner of considering it, the concept will point to forms, which are in that case for itself alone if they are conceived without the proper activity of the singularity or subjectivity within it. (Conceptual) freedom is the very object of philosophy. And these two (i.e. concept and freedom) could be differentiated as the difference between concept and idea.

\section{Realised and Self-Realising Self-relation without Self-reference: Objectivity and more}

Because the concept is the use and elaboration of freedom, it may be the case, that singularity is posited in a non-formal way; self-relation is realised there, and through just such a formal realisation, it is also a case of an existing concept. Objectivity is the implication or that which is achieved in self-relation, only if it is not only formal. ${ }^{38}$ That objectivity could be taken as a negative freedom or as a negative (not attributed out of itself, but posited) selfrelation; it is other, in being really and not formally attributed. (It is just this that demonstrates the reproduction of the non-formal genesis of the concept).

The existing subjectivity, on the other hand, is the specification (as act) of other elements. If, then, there is a concept of self-relation and it is an (own) performance, and not only some formal concerned only it for itself (as formal), then a realised performance posits a relation to itself as not only formal. As the singularisation of such a relation, it is an affirmation, which is no longer merely formal. More specifically, even if the concept does not have the specific power of full realisation (as it is conceived of in ordinary understanding), it is the starting point of the search for realisation of what will follow, namely concerning its performance as such. If the concept or subjectivity is formal, it is attacked as empty or has a problem of its (possible) own emptiness, being only relation to itself. The performance of thinking by thinking, however, is not related to itself as itself, but to itself as an other.

${ }^{38}$ If conceiving is not a formal combination of elements which remain indefinite in thinking, it is rather a modal version of a content taken up and thereby reproduced as actual by its conceiving (as in spirit), so that the determination of the concept is in relation to such 'things' which seem only not themselves to be concepts. 
The objectivity is also a realisation of the minimal form of an existing system of concepts, in as far as the system-thoughts emerge out of a formal exposition of subjectivity. Whereas subjectivity was earlier the formal concept of formal system, it is now posited as contingent, in so far as it has to show its ability to grasp or perform in relation to objectivity, which does not attribute to itself, but which 'realises' a non-formal self-relation. Objectivity is the case of the systematic position (i.e. the system of self-relation), without the possibility of even presenting a self-relation, in as far as self-relation is attributed to formal systems, but only in being attributed, as in a judgment. This singularity is a subsistence of (formal) systematicity, now in the form of objectivity.

The concept of objectivity is a system-thought, in which the content is no longer considered as a formal concept, but is existent to the exclusion of the formal concept. Only the formal concept may expose the relation to itself, whereas this 'objectivity' merely shows or posits its systematicity of being only related itself, without ever conceiving of that relation. After the 'realisation' of formal self-relation, 'objectivity' is taken up as a contental system, which does not present itself immediately as self-relation, but in which the centre as well as the goal (both conceivable self-related forms) may arise. This self-relation is also not out of itself in objectivity, and cannot be conceived of as such, where the self-relation is only a subsistent one.

In cases, however, where the subjectivity of the concept is posited as subjective in objectivity, it is structured as the performance of the concept, such that there is only that kind of performance with the activity. At this point, life, cognition and the absolute idea arise. All of them are true self-relation(s), in which the self-relation is presented as such, and in which the self-relation is the product or performance of the determination itself. In as far truth is congruence, i.e. prestation or performance. ${ }^{39}$

Life, cognition and the absolute idea imply that in every shape of the idea itself, the activity of the concept or the activity of the singularisation of the concept is required ${ }^{40}$. In life, the living animal has to live, to exist as a self-organisation (or a 'self-systematisation'), or to presuppose its concept in order to realise itself. Cognition, which is either theoretical or practical, must be presupposed as the conception of truth or be conceived of as law or as the action; it is the very performance itself-autonomy.

The last stage, the absolute idea as Method, is the freedom of the concept as moving and self-related form. But can such a method still even be called freedom? Is that kind of proper goal really free, or is it only the highest form of necessity as a presupposed genus, as presupposed thought, or a law or as a 'thinking thought', a definitive identity of form, only being itself in its givenness? It would be a mechanical necessity, as speculative dialectics is treated by its critics, if there were nothing but the process from beginning to end. But active and performative freedom realises itself neither as an other nor as an identity only with itself; it produces the concept under the rule of itself (as the essence) of itself; such an affirmation is the performance of its own proper concept which takes up all other moments, thereby liberating them in the concept. The self-relation of the absolute idea is not a (theoretical

${ }^{39}$ L. De Vos, 'Die Wahrheit der Idee', in: A.F. Koch e.o. (ed.), Der Begriff als die Wahrheit. PaderbornMünchen-Wien-Zürich 2003,153-169.

${ }^{40}$ G.W.F. Hegel, Wissenschaft der Logik, GW 12:173-253. 
or descriptive) givenness, but a use of freedom to realise in freedom, that without which the method would never be attained, a personality, which is the active and therefore free selfrelation in everything that could be conceived, or freedom as such ${ }^{41}$.

\section{Conclusion}

In my talk today, I have distinguished in general among four forms of self-relation. The empty but active one is called self-reference, the contental or systematic form is spirit, which is a self-relation in which the self-reference has become a self-knowing without an explicit self-reference. Such a system may be the system of knowledge or the systems of the realisation of spirit's ownness (or freedom). None of these forms, as such, explains the structure of selfrelation itself. Instead, this is accomplished by the conceptual structure of the 'concept' itself. In as far as the subjectivity or activity of the concept is the exposition of its own proper forms, which are all concepts, self-relation is a system and every system is at least a formal selfrelation (for philosophy or logic). This self-relation is therefore not a descriptive term, but presents itself in its own realisation(s). In realising itself, it is not an automaton which would reproduce only itself as itself in itself and which could not be a form of knowledge. Thus, this realisation shows and explains again that the concept is free and definitively free insofar as it is and has its highest form, the idea, which performs what the concept is, that is, a free activity directed towards itself or which is active and therefore free self-relation. To put this another way, in forms of freedom: self-relation is free as abstract in self-reference; it is contental in the forms of spirit; it is formal and systematic in the concept -not considered as merely formal-, and it presents its perfect free performance in the active congruence of the forms of the idea.

\footnotetext{
${ }^{41}$ For the reason(s), why there is no automaton, cfr. H.F. Fulda, G. W. F. Hegel. München 2003, 123-126.
} 